\title{
A NOVELHYBRID BIO-SYSTEM FOR WASTEWATER TREATMENT USING ALGERIAN AGRICULTURAL WASTES
}

\author{
NOWY HYBRYDOWY BIOSYSTEM DO OCZYSZCZANIA ŚCIEKÓW \\ WYKORZYSTUJĄCY ALGIERSKIE ODPADY ROLNICZE
}

\begin{abstract}
The development of a new clean, easy to handle process with similar efficiency to that of the conventional process is one of the most important challenges in green chemistry investigation. In this study, a new hybrid process was investigated; coupling coagulation-flocculation with adsorption using abundant and natural bioproducts (Chitosan and Ammi visnaga). The Chitosan/Ammi visnaga (coagulation/adsorption) system was studied for its Brilliant Green dye removal capacity. This new technique seems to be a good alternative method for wastewater treatment, showing satisfactory results with high rates of elimination that range around $90 \%$.
\end{abstract}

Keywords: Ammi visnaga, chitosan, bio-coagulation, biosorption, bio-system

\section{Introduction}

Water, throughout history, has been an important factor in ensuring human well-being. Currently, one of the most serious environmental problems is the pollution of the hydrosphere, which is largely due to human activity. In both developed and developing countries, the quality of this vital element is deteriorating because of the chemical wastes that are dumped into the environment. Dyes are organic compounds used in many industries: paper, cosmetics, food processing, textiles, agriculture, pharmaceuticals, as well as medical diagnostics [1].

The world production of synthetic dyes is estimated at $800 \cdot 10^{6} \mathrm{~kg} / \mathrm{year}$. Some of these dyes (approximately $140 \cdot 10^{6} \mathrm{~kg} /$ year) are rejected during the fabric making and staining steps [2]. Their elimination is one of the main problems in the liquid waste treatment process. Several types are highly toxic, carcinogenic, mutagenic and difficult to biodegrade $[3,4]$. In water treatment, coagulation and flocculation are treatments that aim to optimize the removal of particles in suspension by the decantation and filtration process. These treatments favor the aggregation of colloidal particles in large and dense aggregates, despite their great use; they still are a source of secondary pollution.

\footnotetext{
${ }^{1}$ Laboratory of Chemical Engineering Saad Dahlab University of Blida, route de SOUMÂA BP 270, 09000 Blida, Algeria, phone +213.549 .168 .611$

${ }^{2}$ Center for Scientific and Technical Research in Physico-Chemical Analysis, Zone Industrielle BP 384, 42004 Bou-Ismail, Tipaza, Algeria

*Corresponding author: sarachikhi10@gmail.com
} 
To minimize these problems, many works show the efficacy of the natural origin compounds, which can be used as alternatives to the chemical coagulants and flocculants. Recently, research has focused on the study of chitinous products and their derivatives and, in particular, chitosan, which is the most economically attractive [5-8].

Its intrinsic properties, abundance and biodegradability are major assets for its use in a respective depollution of the environment $[9,10]$.

The aim of this study is to increase the eliminating effect of chitosan by using it as a coagulant, adding another biomaterial as an adsorbent. Recently, adsorbents have been developed from naturally occurring materials; these adsorbents have become the focus of environmental investigations because of their low cost and biodegradability $[11,12]$. Most conventional adsorption systems use activated carbon despite its production cost and difficult regeneration [13].

This has therefore encouraged researchers by directing them to the treatment processes using less expensive and widely available natural materials. Indeed, the performance and efficiency of this technique depend preponderantly on the nature of the substrate used as an adsorbent, its cost, abundance and regeneration $[14,15]$. In this research we will take part in the Brilliant Green $(B G)$ dye elimination (our pollutant model) using a hybrid system by coupling chitosan $(\mathrm{CH})$ with Ammi visnaga $(\mathrm{AV})$ as a coagulant and adsorbent respectively, taking into consideration the conditions of the coagulation-flocculation/adsorption combination.

\section{Materials and methods}

\section{Chitosan samples}

Chitosan was extracted from Aristeus Antennatus and Aristaeomorpha Foliacea red shrimps through a demineralization, deproteinization and deacetylation that spanned from April to June 2015. The shrimp shells were collected from the Bouharoun port, $45 \mathrm{~km}$ west of Algiers [16]. The chitin exctration from the shells and the chitosan production via deacetylation were all done following the Takaguchi Method [17]. Chitosan is characterized by its degree of deacetylation, viscosity and molecular weight. The degree of deacetylation $(D D)$ is the molar percentage of the $\mathrm{N}$-acetyl groups removal; this parameter influences all the physicochemical properties (molecular weight, viscosity and solubility) of chitosan. The main characteristics of chitosan are shown in Table 1.

Main characteristics of chitosan

\begin{tabular}{|c|c|}
\hline Common name & Chitosan \\
\hline Chemical name & B 1,4 poly D glucosamine \\
\hline Brute formula & $\left(\mathrm{C}_{8} \mathrm{H}_{3} \mathrm{NO}_{5}\right)_{\mathrm{n}}$ \\
\hline Solubility in water & Insoluble \\
\hline Solubility in acetic acid & Soluble homogenous \\
\hline Solubility in NaOH & Insoluble \\
\hline Molar mass [g. mol $\left.^{-1}\right]$ & 200,000 \\
\hline$D D A[\%]$ & 75 \\
\hline Water content [\%] & 1.5 \\
\hline Ashes content [\%] & $0.5 \pm 0.4$ \\
\hline Lipid content [\%] & 0.9 \\
\hline Colour & Beige \\
\hline
\end{tabular}


To prepare the chitosan solution, $100 \mathrm{mg}$ of chitosan were dissolved in $100 \mathrm{~cm}^{3}$ of $85 \%$ acetic acid under agitation and subsequently hydrated overnight at room temperature $(293.1 \pm 2.0) \mathrm{K}$ in $99 \mathrm{~cm}^{3}$ of demineralised water. The final polymer solution was maintained at $\mathrm{pH} \mathrm{4}$. All reagents used in the experiment were of laboratory grade. They were diluted to the concentration required for the steps with distilled water. All chemicals were used without further purification. The Brilliant Green dye used was purchased from Biochem Chemopharma and used without purification; the purity was taken into account when calculating the true concentrations. The characteristics and wavelength are summarized in Table 2. The residual concentration was measured by $U V$-Visible spectrophotometer (SHIMAZDU).

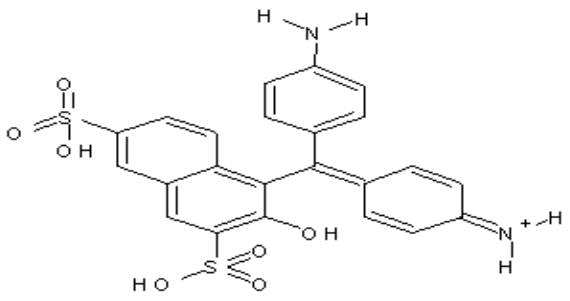

Fig. 1. Molecular structure of $B G$

Characteristics of studied dye

\begin{tabular}{|c|c|}
\hline Dye & C.I. Acid Green \\
\hline CAS registry number & $3087-16-9$ \\
\hline Molecular formula & $\mathrm{C}_{27} \mathrm{H}_{25} \mathrm{~N}_{2} \mathrm{NaO}_{7} \mathrm{~S}_{2}$ \\
\hline Molecular weight $\left[\mathrm{g} \cdot \mathrm{mol}^{-1}\right]$ & 576.616 \\
\hline Purity [\%] & 80 \\
\hline$\lambda[\mathrm{nm}]$ & 625.0 \\
\hline
\end{tabular}

\section{Coagulation-floculation process}

All of these experiments were performed at room temperature $(293.1 \pm 2.0) \mathrm{K}$. Each dye solution with a controlled $\mathrm{pH}$ (using $0.1 \mathrm{M} \mathrm{HCl}$ or $0.1 \mathrm{M} \mathrm{NaOH}$ ) was mixed after adding polymer solution under rapid stirring $(200 \mathrm{rpm})$ for $10 \mathrm{~min}$ followed by slow stirring (40 rpm) for $20 \mathrm{~min}$. The initial $\mathrm{pH}$ of the solution was fixed at 4 . The added volume of chitosane solution contains $10 \%$ water (taken into account for calculating the true concentration) they were fixed to $\left(10,20,30\right.$ and $\left.40 \mathrm{~g} \cdot \mathrm{dm}^{-3}\right)$. Samples were collected after 20 min of settling-time at the top $(1 \mathrm{~cm})$ of the solution surface using a syringe and filtered through a $1.2 \mu \mathrm{m}$ Whatman filter (the amount of dye retained on the membrane was below $2 \%$ ) and analyzed by $U V$-Visible spectrophotometer at the maximum absorbance peak.

\section{Elimination of $B G$ by $C H / A V$ system}

The tests of the coagulation and absorption combination were carried out in series; the adsorbent was directly introduced into the solutions obtained after coagulation (after 20 minutes of flocculation). In the first part, we were interested in studying the adsorption of the $B G$, by a natural adsorbent that is widely available in northern Algeria. Its common name is the Khella, or Noukha in the Maghreb, also called Ammi visnaga 
(Visnagadaucoides), is an annual or biennial herbaceous plant of the family Apiaceae. Ammi visnaga is an eternal tree widely distributed in the Mediterranean basin and mainly cultivated in Egypt, Morocco and Tunisia, but also in Argentina, Chile, Mexico, and the southern United States on a larger scale [18]. This plant is well known by its pharmaceutical applications for the treatment of some disease such as angina, supportive treatment for mild obstruction of the respiratory tract in asthma, bronchial asthma or spastic bronchitis, and postoperative treatment of conditions associated with the presence of urinary calculit [19].

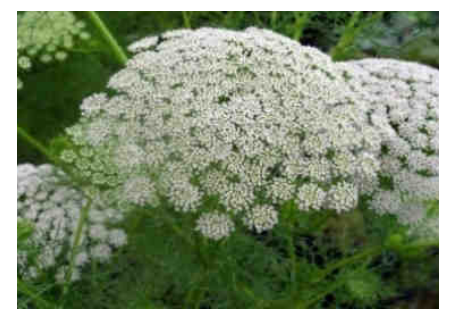

Fig. 2. Plant of Ammi visnaga

\section{Biomass preparation (Ammi visnaga extraction waste)}

The biomass used was obtained from the research center in analytical chemistry and physics (CRAPC, Algeria) [20], as a solid waste of the Ammi visnaga extraction and used without further treatment. The biomass was washed repeatedly with distilled water (conductivity $0.5 \mathrm{~S} \cdot \mathrm{cm}^{-1}$ and $\mathrm{pH}$ 6) until the washing water became colorless, the $U V$-VIS absorbance spectrum coincides with that of the distilled water, and the electric conductivity and $\mathrm{pH}$ remain constant. The washed biomaterials were dried in an air oven at $353 \mathrm{~K}$ for $24 \mathrm{~h}$. The biomass was then crushed and sieved repeatedly to get a powder of $200 \mu \mathrm{m}$; the achieved biomaterial was stored in desiccators until use. The main characteristics of the biosorbent are presented in Table 3.

Table 3

Main characteristics of Ammi visnaga

\begin{tabular}{|c|c|}
\hline Common name & Ammi visnaga \\
\hline Chemical name & Khellin \\
\hline Chemical formula & $\mathrm{C}_{14} \mathrm{H}_{12} \mathrm{O}_{5}$ \\
\hline Molecular weight $\left[\mathrm{g} \cdot \mathrm{mol}^{-1}\right]$ & 260.24 \\
\hline Colour & Beige \\
\hline
\end{tabular}

Coupling coagulation to adsorption

In order to fix the optimum coagulant/adsorbent ratio, a series of experiments was carried out by introducing variable coagulant amounts $\left(10,20\right.$, and $\left.30 \mathrm{mg} \cdot \mathrm{dm}^{-3}\right)$ followed by a second series of adsorbent $(0.5,1,2$ and $3 \mathrm{~g})$ in a $100 \mathrm{~cm}^{3}$ volume of aqueous dye solution at different concentrations $\left(1,5,10,15,20\right.$ and $\left.25 \mathrm{mg} \cdot \mathrm{dm}^{-3}\right)$.

The whole is subjected to magnetic stirring $(200 \mathrm{rpm})$ at room temperature (293.1 \pm 2.0$)$ K. Sampling is carried out at different time intervals ranging from 0 to 80 minutes of contact using a syringe on the surface of the solution $(1 \mathrm{~cm})$. The solutions are analyzed by UV-Visible spectrophotometer at the appropriate wavelength of 
$625 \mathrm{~nm}$. The results are expressed as an elimination percentage $E$ [\%], calculated by the following formula:

$$
E=\frac{A b s^{0}-A b s}{A b s^{0}}
$$

where $A b s^{0}$ is initial absorbance, $A b s$ is final absorbance.

\section{Research results}

\section{Application to coagulation-flocculation}

Zeng et al. [21] found a novel composite of chitosan flocculant that has been prepared according to the weight proportions of $1 \%$ chitosan: $2 \%$ Poly Aluminum Chloride $(P A C)$ : sodium silicate $=1: 100-200: 10-20(\mathrm{w} / \mathrm{w})$. Compared with a conventional flocculant such as PAC, the percentage removal of Chemical Oxygen Demand (COD), Suspended Solids $(S S)$ and aluminum ions $\left(\mathrm{Al}^{3+}\right)$ in the treated water was enhanced by $1.8-23.7 \%, 50 \%$ and $61.2-85.5 \%$ respectively while the running cost was reduced to $34 \%$ using this novel composite. In this study we investigate the determination of the chitosan coagulation capacity towards sulfonic dyes ( $B G$ as a model); the chitosan was used as a primary agent of coagulation and flocculation. After the coagulated solution's decantation, the absorbance is measured. The chitosan and dye concentration will be studied in order to determine their influence on the rate of the dye removal. The elimination rate evaluation of the Brilliant Green at equilibrium is followed by the equation (1).

\section{Effect of chitosan dose}

The determination of the chitosan dose is an important parameter for its performance as a coagulant, an insufficient dosage or an overdose may influence the coagulation-flocculation phenomenon, for this, it is necessary to determine the appropriate concentration domain for better abatement rate. The graphic representation (Fig. 3) indicates the acceptable elimination rates for chitosan used in order of $50 \%$ for a dosage of $10 \mathrm{mg} \cdot \mathrm{dm}^{-3}$. Compared to metal salts, the removal of such dye concentrations requires $40 \mathrm{mg} \cdot \mathrm{dm}^{-3}$ of sulphate alumina, in this case, it can be deduced that the use of chitosan as a primary coagulant requires a small concentration range to be effective. Economically speaking this conclusion is very important as the sludge generated by this method will be of a lesser amount and toxicity than those obtained by the metallic salts. The coagulation flocculation results from various mechanisms including electrostatic attraction, sorption (protonated amine groups), and deriding (high molecular weight of polymer) [10]. The protonated amine groups make the chitosan positively charged, like all polymers, the chitosan coagulation mechanism is the neutralization of the charges under the effect of its cations present along the polymer chain, the anionic dye, bearing sulfonic groups, is attracted electrostatically by protonated amine groups, it allows the neutralization of the dye's anionic charges, which can bind together and settle, one molecule of chitosan can interact with several dye molecules contributing to the formation of flocs [22] due to the presence of a stoichiometric reaction between the dye and chitosan; hence the efficiency of chitosan in the treatment of anionic dyes depends on its deacetylation degree, molecular weight and its concentration [23], when the amine groups are totally neutralized by the dye charges, the maximum rate of elimination will be assumed, for this reason overdosage with chitosan leads to restabilization of the suspension due to the excess of protonated amine groups in the solution and then decreasing the efficiency of the process [16]. As confirmed 
by the results obtained, beyond $10 \mathrm{mg} \cdot \mathrm{dm}^{-3}$, the assay in chitosan shows a significant decrease in the dye removal rate.

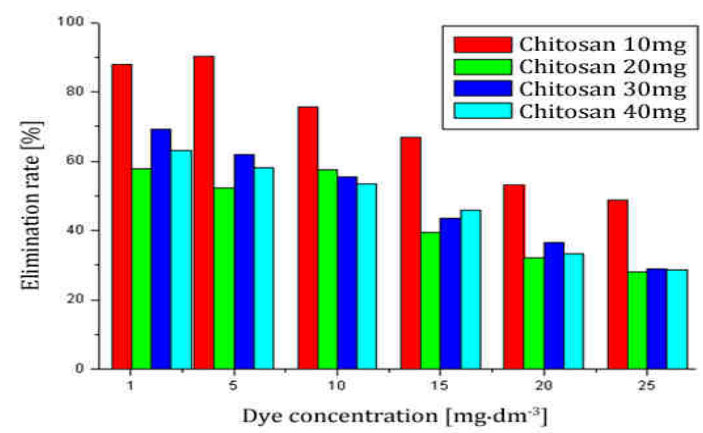

Fig. 3. Effect of dye concentration and coagulant dose on elimination rate

\section{Pollutant concentration effect (dye)}

The results shown in Figure 3 indicate the $B G$ concentration effect on the process efficiency, these results show that an increase in dye concentration in the solution results in a decrease in the dye elimination, this is explained by the fact that the chitosan reacted by charge neutralization, the sulphonic group-bearing dye is electro-statically attracted to the protonated amine groups of the chitosan, the maximum elimination rate will be obtained when the amines groups are totally neutralized by the dye charges, at higher dye concentrations the chitosan will have no effect. Guibal and Roussy [24] confirm a presence of stoichiometric reaction between the dye and chitosan by the interaction of the dye's various anionic groups (sulphonic) with the chitosan's different protonated amine groups (inter- and intra-chain associations).

\section{Elimination of $B G$ by the chitosan/Ammi visnaga system}

To visualize the effectiveness of coagulation-floculation and adsorption to eliminate dyes, we performed the coagulation-flocculation coupled with adsorption. The effect of the initial dye concentration was studied by varying the initial concentration at self-equilibrium $\mathrm{pH}$ and room temperature. The different results obtained were expressed using percentage of elimination $E[\%]$ curves as a function of time and initial concentration according to the following equation:

$$
E=f(t)
$$

Figure 4 shows the evolution of the adsorbed amount of the solute as a function of time. In general, the appearance of these curves makes it possible to highlight two zones:

- The first is characterized by a strong biosorption of the adsorbate from the first minutes of adsorption. The $A V$ contact time was obtained at an initial concentration of $25 \mathrm{mg} \cdot \mathrm{dm}^{-3}$. The rapidity of the adsorption at start-up can be interpreted by the number of available active sites to the surface of the adsorbent material.

- The second is where the biosorption of the solute $(B G)$ is maximal with elimination rates exceeding $90 \%$, at this stage we can consider that the system is in a pseudo-equilibrium phase between the adsorption and desorption rates. 
The equilibrium time is very rapid (10 to $15 \mathrm{~min}$ ). On the basis of these results, it is clear that the affinity of the biosorbent $(A V)$ with the $B G$ is very important.

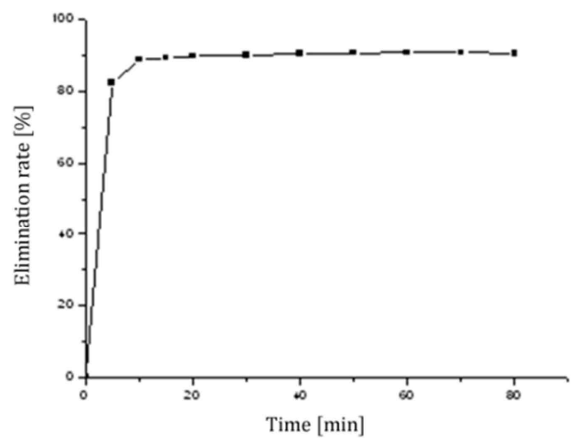

Fig. 4. Effect of contact time on biosorption of $B G$ on $A V$ at $\mathrm{pH}=4, T=295 \mathrm{~K}, m=2 \mathrm{~g}$

\section{Effect of dye concentration on adsorption}

Figure 5 shows the evolution of the quantities of the dye adsorbed by the $A V$ as a function of time at different initial concentrations. It is noted that a higher initial concentration leads to an increase in the biosorption capacity of the dye. This is essentially due to a large driving force which overcomes all the resistances to the mass transfer of the dye between the two phases (aqueous and solid) produced by the increase in the initial concentration of the dye. Moreover, we notice that the kinetic of adsorption is rapid at the beginning of the process and becomes much slower over time to reach a state of pseudo-equilibrium which has remained constant as a function of the concentration. This indicates the possibility of a unitary layer formation of the molecules at the external interface of Ammi visnaga. In fact, the diffusion of dye molecules in Ammi visnaga particles can regulate the rate of adsorption at higher initial concentrations. In our case, a contact time of $15 \mathrm{~min}$ was considered sufficient for the adsorption of the dye to reach the pseudo-equilibrium state.

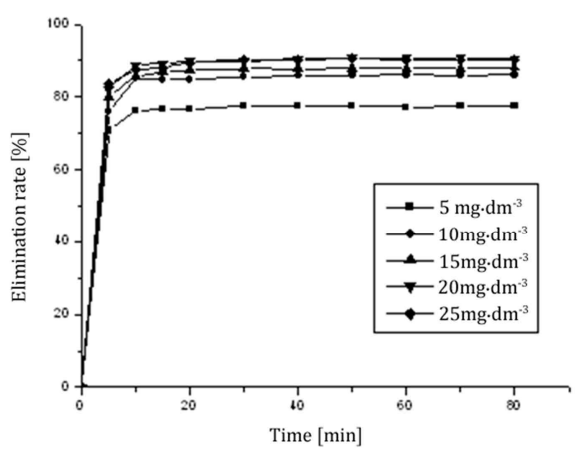

Fig. 5. Initial concentration effect of $B G$ on the removal efficiency biosorption on Ammi visnaga vs time at $\mathrm{pH}=4, T=295 \mathrm{~K}, m=2 \mathrm{~g}$ 


\section{Effect of biosorbent concentration}

In order to know the mass necessary and sufficient to increase the rate of $B G$ elimination, the mass effect of our biosorbent on the rate of dye removal was studied and the results obtained are shown in histogram (Fig. 6). The dosage of Ammi visnaga is particularly important because it determines the extent of discoloration. The used biosorbent amount was varied from 0.5 to $3 \mathrm{~g}$. Figure 6 shows that the retained quantities of dye are maximal for the amount of $A V$ equal to 1,2 , and $3 \mathrm{~g}$. This is explained by the availability of the biosorbent. When the mass of the biosorbent is increased, the number of available adsorption locations for the biosorbent-adsorbate interaction is also increased. The elimination rate increases together with the adsorbent mass due to the availability of a large active surface area. Our results are similar to some works proving that the increase of the sorbent doses leads to a diminishing sorption capacity [25-27].

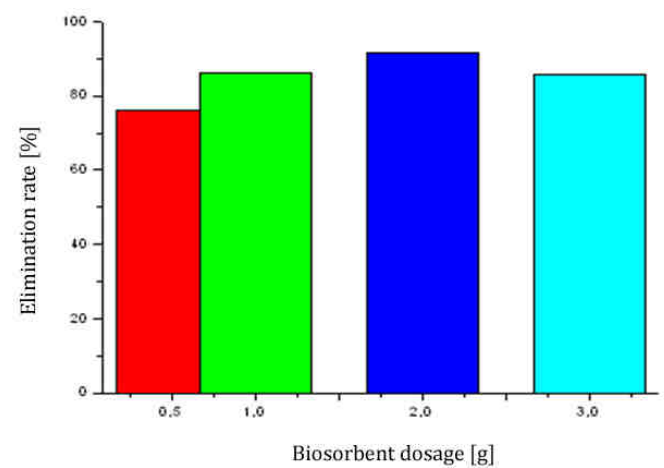

Fig. 6. Effect of $A V$ dosage on elimination rate of $B G$

\section{Effect of mixture chitosan - Ammi visnaga}

For the improvement of the $B G$ elimination efficiency, a combination of coagulation-adsorption with the chitosan/Ammi visnaga system was chosen; the results obtained are presented in the histograms below. By analyzing the results, we note that the elimination of $B G$ with the system $(C H / A V)$ by a combination of the two processes (coagulation / bio-sorption) leads to a total dye elimination rate increase that exceeds $90 \%$ (Fig. 7), compared to those obtained for coagulation alone. Syafalni et al. [28] state that the addition of bentonite can be used as an adjunct to accelerate coagulation-flocculation or vice versa, as it helps to improve the consistency and density of flocs. Although the conditions used in the case of coagulation alone are optimal, the addition of bentonite improves the elimination rate [28, 29]. However, we observed that the addition of the Ammi visnaga biomass to the solution in the presence of chitosan, improves the coagulation-flocculation efficiency with the latter. The influence of the dye concentration effect on the system $(\mathrm{CH} / \mathrm{AV})$ observations allow us to deduce a diminution in the elimination efficiency at low initial dye concentrations $\left(5 \mathrm{mg} \cdot \mathrm{dm}^{-3}\right.$, compared to 15,20 and $25 \mathrm{mg} \cdot \mathrm{dm}^{-3}$ ) which were more than $96 \%$, this is explained by the large amount of the chitosan's amine groups and the Ammi visnaga's active surface sites that compete for the retention of $B G$ leading to a re-destabilization of the polluting charge. 
a)

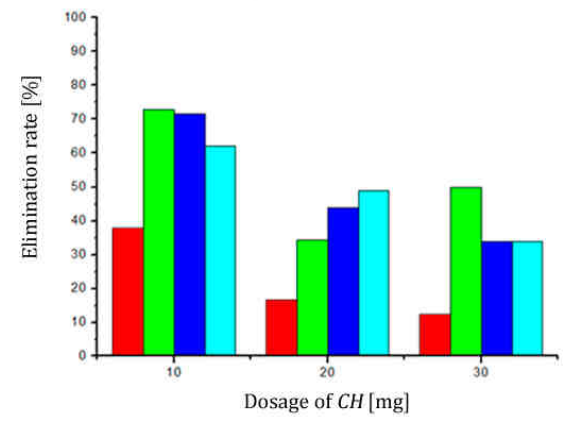

c)

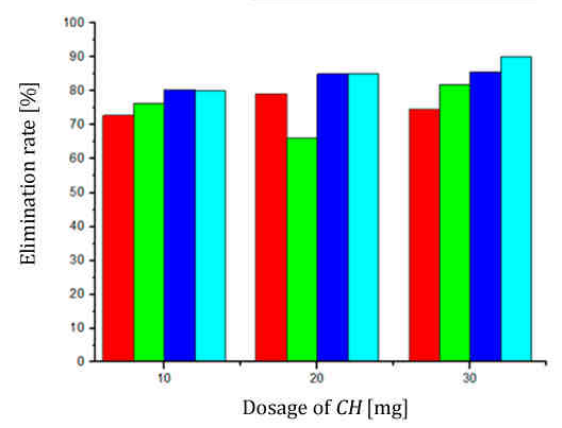

e)

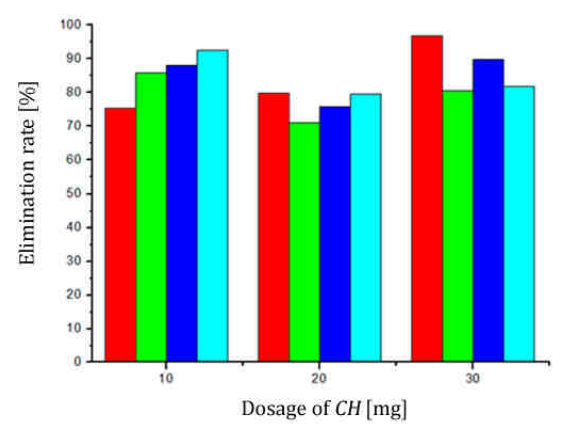

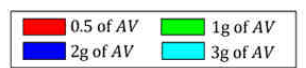

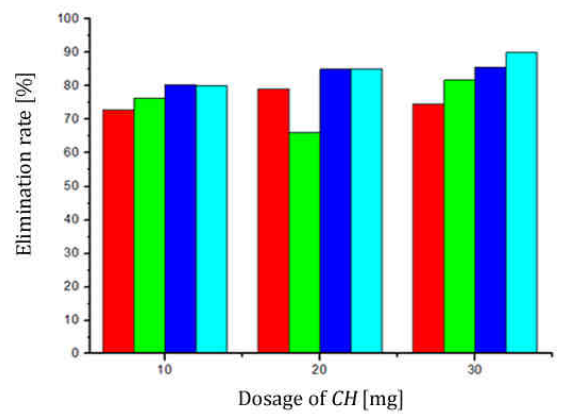

d)
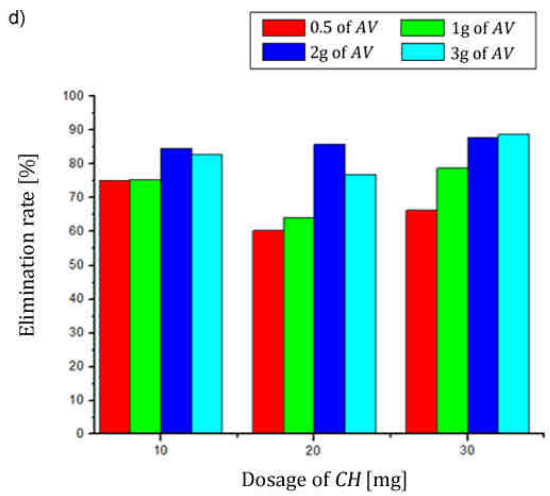

f)
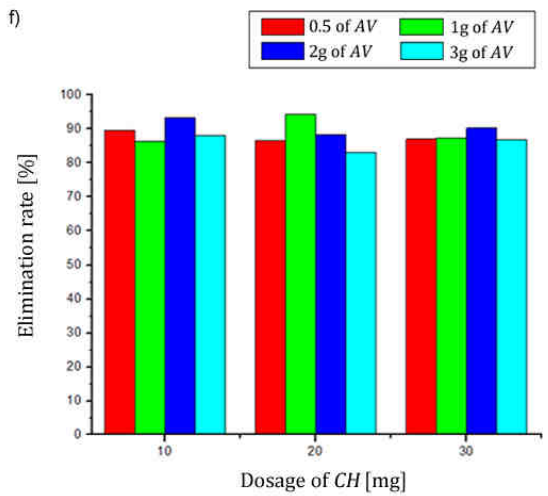

Fig. 7. Effect of mixture $C H-A V$ on elimination rate: a) using $1 \mathrm{mg} \cdot \mathrm{dm}^{-3}$ of $B G$, b) using $5 \mathrm{mg} \cdot \mathrm{dm}^{-3}$ of $B G, \mathrm{c})$ using $10 \mathrm{mg} \cdot \mathrm{dm}^{-3}$ of $\left.B G, \mathrm{~d}\right)$ using $15 \mathrm{mg} \cdot \mathrm{dm}^{-3}$ of $\left.B G, \mathrm{e}\right)$ using $20 \mathrm{mg} \cdot \mathrm{dm}^{-3}$ of $B G, \mathrm{f}$ ) using $25 \mathrm{mg} \cdot \mathrm{dm}^{-3}$ of $B G$

In order for the $A V$ to retain its adsorptive power in the solution, it was introduced after the coagulant; this allowed it optimal dye elimination. Strand et al. [30] confirm that the coagulation-adsorption capacity is better than the coagulation-only capacity. The decrease 
of the latter is probably due to the weak bonds formed between ions of the adsorbate and the activated sites of the adsorbent; these ions may be exchanged from first contact with the chitosan's amine groups. It may therefore be suggested that the mechanism involved during coagulation-flocculation of the $C H / A V$ system in the presence of $B G$ is an ion exchange between the chitosan's $\left(-\mathrm{NH}_{3}{ }^{+}\right)$groups and the dye's sulfonic groups adsorbed on the Ammi visnaga surface (as adsorbent), followed by forming coordination bonds between the chitosan's amine groups $\left(-\mathrm{NH}_{2}\right)$ and the sulfur ions adsorbed by the Ammi visnaga.

\section{Conclusions}

Now, chitin and chitosan were commercially prepared from crab and shells. In the present investigation chitin and chitosan were isolated from the Aristeus antennatus and Aristaeomorpha foliacea red shrimps through chemical extraction by demineralization, deproteinization and deacetylation. The used conditions provided a chitosan with anacceptable degree of deacetylation $(75 \%)$ and an average molecular weight of $191.5 \mathrm{kDa}$. The solubility of Chitosan in acetic acid proved its efficiency for the coagulation-flocculation of Brilliant Green. In acidic solutions, the charge neutralization was responsible for the dye removal. As a result, the wastewater from the textile industry can be treated by using chitosan via the coagulation-flocculation process which is more favorable in wastewater treatment due to its environment-friendly characteristics. Moreover, the coupling of the coagulation-flocculation technique to the adsorption using bio-products has been very satisfactory from a technical point of view, the introduction of Ammi visnaga as an adsorbent to chitosan flocculation coagulation has greatly improved the elimination rate which exceeded in some cases $95 \%$. The coagulation-adsorption system $(\mathrm{CH} / \mathrm{AV})$ also improves the total dye removal efficiency even at high concentrations whose initial dye concentration had no influence on the effectiveness of the system. Thereafter, the total yield is always high.

The adsorption affinities of the $B G$ dye onto Ammi visnaga combined with the Chitosan solution were evaluated as very satisfactory. The use of the adsorption properties of Ammi visnaga during the flocculation can thus seem like an interesting solution that reacts in reducing the formation of organohalogenous compounds such as THMs at the purification stations when the chlorination point is displaced downstream of the clarification phase. It also seems like a very interesting alternative process for the reuse of wastewater. The use of such processes allows the preservation not only for the purification stations (membranes) but also the environment, producing lower amounts of biodegradable and non-toxic sludge.

\section{References}

[1] Tjoon TT, Ling WL. Removal of Dyes and Pigments from Industrial Effluents. Advan Water Treat Pollution Prevention. 2012;65-93. DOI: 10.1007/978-94-007-4204-8_4.

[2] Ben Mansour H, Boughzala O, Dridi D, Barillier D, Chekir-Ghedira L, Mosrati R. Textile dyes sources of water contamination: screening for toxicity and methods of treatmen. J Water Sci. 2011;24:209-238. DOI: 10.7202/1006453ar.

[3] Alahiane S, Qourzal S, El Ouardi M, Belmouden M, Assabbane A, AitIchou Y. Adsorption and photocatalytic degradation of indigo carmine dye in aqueous solutions using $\mathrm{TiO}_{2} / \mathrm{UV} / \mathrm{O}_{2}$. J Mater Environ Sci. 2014;4:239-250. https://www.jmaterenvironsci.com/Document/vol4/vol4_N2/30-JMES-3582013-Alahiane.pdf.

[4] Chatterjee S, Lee MW, Woo SH. Adsorption of Congo red by chitosan hydrogel beads impregnated with carbon nanotubes. Bioresour Technol. 2010;101:1800-1806. DOI: 10.1016/j.biortech.2009.10.051. 
[5] Da Sacco L, Masotti A. Chitin and chitosan as multipurpose natural polymers for groundwater arsenic removal and $\mathrm{As}_{2} \mathrm{O}_{3}$ delivery in tumor therapy. Mar Drugs. 2010;8:1518-1525. DOI: 10.3390/Md8051518.

[6] Sanny V, Mallikarjuna Nn, Rajender Sv. Porous nitrogen-enriched carbonaceous material from marine waste: Chitosan-derived carbon nitride catalyst for aerial oxidation of 5-hydroxymethylfurfural (HMF) to 2,5 furandicarboxylic acid. Scientific Reports. 2017;7:13596. DOI: 10.1038/s41598-017-14016-5.

[7] Tomczak E, Tosik P. Sorption equilibrium of azo dyes Direct Orange 26 and Reactive Blue 81 onto a cheap plant sorbent. Ecol Chem Eng S. 2014;21:435-445. DOI: 10.2478/eces-2014-0032.

[8] Machowicz-Stefaniak Z, Zalewska E. Occurrence of Colletotrichum dematium on selected herbs species and preparations inhibiting pathogen's growth and development in vitro. Ecol Chem Eng $\mathrm{S}$. 2011;18:465-478. https://drive.google.com/file/d/1-yytkc9anjcjUlKQvfujbca9BZJz_fG5/view.

[9] Wen YZ, Liu WQ, Fang ZH, Liu WP. Effects of adsorption interferents on removal of Reactive Red 195 dye in wastewater chitosan. J Environ Sci China. 2005;17:766-9. DOI: 100120742 (2005) 0520766204.

[10] Kofuji K, Qian CJ, Nishimura M, Sugiyama I, Murata Y, Kawashima S. Relationship between physicochemical characteristics and functional properties of chitosan. Euro Polymer J. 2005;41:2784-2791. DOI: 10.1016/j.eurpolymj.2005.04.041.

[11] Kamaruddin MA, Mohd SY, Hamidi AA, Muhd NI. Preparation and characterization of composite embedded clinoptilolite for the removal of color and lead from textile waste water. Int J Scien Resear in Inventions and New Ideas (IJSRIN). 2013;1(2): 37-47. DOI: 10.12983/ijsrin-2013-p037-047.

[12] Degbe AK, Koriko M, Tchegueni S, Aziable E, Tchakala I, Hafidi M, et al. Biosorption of methylene blue solution: Comparative study of the cactus (Opuntia ficusindica) of Lmé (CL) and Marrakech (CM). J Mater Environ Sci. 2016;7:4786-4794. https://www.jmaterenvironsci.com/Document/vol7/vol7_N12/505JMES-2575-Degbe.pdf.

[13] Fil BA, Korkmaz M, Ozmetin C. Application of nonlinear regression analysis for methyl violet (MV) dye adsorption from solutions onto illite clay. J Disp Sci Technol. 2016;37,991-1001. DOI: 10.1080/01932691.2015.1077455.

[14] Albariji S, Alamine M, Kabli H, Lacherai A, El Bourine A. Treatment and recovery of wood by-products, application to the elimination of industrial dyes. Comptes Rendus Chimie. 2006;9:1314-1321. DOI: 10.1016/j.crci.2006.05.006.

[15] Jerold M, Sivasubramanian V. Biosorptive removal of malachite green from aqueous solution using brown marine macro algae Sargassums swartzii. Des Water Treat. 2016;57:25288-25300. DOI: $10.2166 /$ wst.2016.513.

[16] Chikhi S, Bouzid B, Hamitouche A. Extraction characterization and application of biocoagulant for treating dyes containing solution using aristeusantenntus and aristaeomorphafoliacea red shrimps. Iner Resear J Public Environ Health. 2017;4:249-258. DOI: 10.15739/irjpeh.17.029.

[17] Jothi N, Kunthavai Nachiyar R. Identification and Isolation of chitin and chitosan from cuttle bone of Sepia prashadi Winckworth, 1936. Global J Biotechnol Biochem. 2013;8:33-39. DOI: 10.5829/idosi.gjbb.2013.8.2.1107.

[18] Plant Encyclopaedia. Ammivisnaaga (L.) lam. (Khella). Copyright 2012. https://www.avogel.ch/fr/encyclopaedie-plantes/ammi_visnaga.php. 26.10.2017.

[19] Al-Snafi AE. Chemical constituents and pharmacological activities of Ammi Majus and Ammi Visnaga a Review. Inter J Pharm Sci Resear. 2013;03:257-265. https://www.researchgate.net/publication/313702903.

[20] Nouri L, Bendjama Z, Hamitouche A, Boumaza S, Kaouah F, Trari M, et al. Optimization of a novel biocomposite synthesis (Ammi visnaga extraction waste/alginate) for $\mathrm{Cd}^{+2}$ biosorption. Inter $\mathrm{J}$ Biol Macromol. 2015;80:588-595. DOI: 10.1016/j.ijbiomac.2015.07.026.

[21] Zeng D, Wu J, Kennedy F. Application of a chitosan flocculant to water treatment. Carbohy Poly. 2008;71:135-139. DOI: 10.1016/j.carbpol.2007.07.039.

[22] Szygula A, Guibal E, Ruiz M, Sastre AM. The removal of sulphonated azo-dyes by coagulation with chitosan. Colloid Sur A. 2008;330:219-226. DOI: 10.1016/j.colsurfa.2008.08.001.

[23] Medjahed K, Tennouga L, Mansri A, Chetouani A, Hammouti B. Interaction between poly (4-vinylpyridinegraft-bromodecane) and textile blue basic dye by pectrophotometric study. Resear Chem Interme. 2012;39:3199-3208. DOI: 10.1007/s11164-012-0832-2.

[24] Guibal E, Roussy J. Coagulation and flocculation of dye-containing solutions using a biopolymer (chitosan). React Funct Polymer. 2007;67,33-42. DOI: 10.1016/j.reactfunctpolym.2006.08.008.

[25] Kilic M, Varol EA, Pütün AE. Adsorptive removal of phenol from aqueous solutions on activated carbon prepared from tobacco residues: equilibrium, kinetics and thermodynamics. $\mathrm{J}$ Hazard Mater. 2011;189:397-403. DOI: 10.1016/j.jhazmat.2011.02.051.

[26] Zhu Y, Kolar P. Adsorptive removal of p-cresol using coconut shell-activated char. J Env Chem Eng. 2014;2:2050-2058. DOI: 10.1016/j.jece.2014.08.022. 
[27] Das L, Kolar P, Osborne JA, Classen JJ. Adsorption of p-cresol on granular activated carbon. Agri Eng Int. 2012;14:37-49. http://www.cigrjournal.org/index.php/Ejounral/article/view/2171/1662.

[28] Syafalni S, Abustan I, Siti Nor FZ, Mohd HZ, Rafini AR. Raw water treatment using bentonite-chitosan as a coagulant. Water Sci Technol: Water Supply. 2012;12:480-488. DOI: 10.2166/ws.2012.016.

[29] Assad E, Azzouz A, Nistor D, Urus AV, Sajin T, Miron DN, et al. Metal removal through synergic coagulation flocculation using an optimized chitosan-montmorillonite system. App Clay Sci. 2007;37:258-274. DOI: 10.1016/j.clay.2007.02.007.

[30] Strand SP, Vårm KM, Østgaard K. Interactions between chitosans and bacterial suspensions: adsorption and flocculation. Colloids and Surfaces B: Biointerfaces. 2003;27:71-81. DOI: 10.1016/S0927-7765(02)00043-7. 